\title{
Chocolate equals stop : chocolate-specific inhibition training reduces chocolate intake and go associations with chocolate
}

Citation for published version (APA):

Houben, K., \& Jansen, A. (2015). Chocolate equals stop : chocolate-specific inhibition training reduces chocolate intake and go associations with chocolate. Appetite, 87, 318-323.

https://doi.org/10.1016/j.appet.2015.01.005

Document status and date:

Published: 01/01/2015

DOI:

10.1016/j.appet.2015.01.005

Document Version:

Publisher's PDF, also known as Version of record

Document license:

Taverne

Please check the document version of this publication:

- A submitted manuscript is the version of the article upon submission and before peer-review. There can be important differences between the submitted version and the official published version of record.

People interested in the research are advised to contact the author for the final version of the publication, or visit the DOI to the publisher's website.

- The final author version and the galley proof are versions of the publication after peer review.

- The final published version features the final layout of the paper including the volume, issue and page numbers.

Link to publication

\footnotetext{
General rights rights.

- You may freely distribute the URL identifying the publication in the public portal. please follow below link for the End User Agreement:

www.umlib.nl/taverne-license

Take down policy

If you believe that this document breaches copyright please contact us at:

repository@maastrichtuniversity.nl

providing details and we will investigate your claim.
}

Copyright and moral rights for the publications made accessible in the public portal are retained by the authors and/or other copyright owners and it is a condition of accessing publications that users recognise and abide by the legal requirements associated with these

- Users may download and print one copy of any publication from the public portal for the purpose of private study or research.

- You may not further distribute the material or use it for any profit-making activity or commercial gain

If the publication is distributed under the terms of Article $25 \mathrm{fa}$ of the Dutch Copyright Act, indicated by the "Taverne" license above, 
Research report

\title{
Chocolate equals stop. Chocolate-specific inhibition training reduces chocolate intake and go associations with chocolate
}

\author{
Katrijn Houben *, Anita Jansen \\ Department of Clinical Psychological Science, Faculty of Psychology and Neuroscience, Maastricht University, PO BOX 616, Maastricht 6200 MD, The \\ Netherlands
}

\section{A R T I C L E I N F O}

\section{Article history:}

Received 23 September 2014

Received in revised form 6 January 2015

Accepted 9 January 2015

Available online 13 January 2015

\section{Keywords:}

Inhibition

Training

Food intake

Stop associations

\begin{abstract}
A B S T R A C T
Earlier research has demonstrated that food-specific inhibition training wherein food cues are repeatedly and consistently mapped onto stop signals decreases food intake and bodyweight. The mechanisms underlying these training effects, however, remain unclear. It has been suggested that consistently pairing stimuli with stop signals induces automatic stop associations with those stimuli, thereby facilitating automatic, bottom-up inhibition. This study examined this hypothesis with respect to food-inhibition training. Participants performed a training that consistently paired chocolate with no go cues (chocolate/no-go) or with go cues (chocolate/go). Following training, we measured automatic associations between chocolate and stop versus go, as well as food intake and desire to eat. As expected, food that was consistently mapped onto stopping was indeed more associated with stopping versus going afterwards. In replication of previous results, participants in the no-go condition also showed less desire to eat and reduced food intake relative to the go condition. Together these findings support the idea that food-specific inhibition training prompts the development of automatic inhibition associations, which subsequently facilitate inhibitory control over unwanted food-related urges.
\end{abstract}

(c) 2015 Elsevier Ltd. All rights reserved.

\section{Introduction}

Globally, obesity has nearly doubled since 1980 and continues to rise unabated (Finucane et al., 2011). It is the fifth leading risk factor for deaths worldwide by placing individuals at the risk of cardiovascular diseases, diabetes, musculoskeletal disorders and cancer (World Health Organization, 2009). In the interest of individual and public health, this obesity pandemic calls for effective interventions to reduce excessive bodyweight and obesity, and thereby obesity-related morbidity and mortality. Ultimately, obesity can be explained as the result of a simple equation: Excessive calorie consumption, without extra energy expenditure, converts calories into fat deposits and results in weight gain. The implications are relatively straightforward: In order to achieve weight loss, one needs to reduce daily caloric intake, increase psychical activity, or do both. For many, however, this equation is easily understood but difficult to balance.

Self-control may be the critical factor in this knowledgebehavior gap. Self-control refers to "the ability to override or change one's inner responses, as well as to interrupt undesired behavioral tendencies (such as impulses) and refrain from acting on them" (Tangney, Baumeister, \& Boone, 2004, p. 274). Similarly, contemporary

\footnotetext{
* Corresponding author.

E-mail address: K.Houben@maastrichtuniversity.nl (K. Houben).
}

dual-process theories state that failures of self-control occur due to the inability to inhibit impulses that are activated by salient temptations (e.g., Hofmann, Friese, \& Strack, 2009). Specifically, dualprocess models like the Reflective-Impulsive Model (Hofmann et al., 2009; Strack \& Deutsch, 2004) describe two qualitatively different processes and how they guide behavior: The reflective system represents a slow-acting and controlled system that serves to direct behavior toward long-term goals and personal standards. The impulsive system operates in a relatively automatic manner wherein responses to stimuli are derived from affective and motivational associations with these stimuli. Whenever a conflict between these two systems arises, enacting the goal-directed behavior (e.g., stick to a diet) requires the inhibition of automatic impulses (e.g., indulge in chocolate cake). Importantly, the successful resolution of such self-control conflicts critically depends on inhibitory control capacity. Hence, the inability to adhere to the simple principles of the energy balance equation could be due to inhibitory control failure: When unable to actively inhibit behavioral impulses that are incompatible with one's goals, such as wanting to indulge in a delicious piece of chocolate cake when trying to diet, impulses will dictate behavior at the expense of becoming overweight. Individual differences in inhibitory control may thus very well explain why some people do not succeed in resisting the temptation of palatable, high calorie foods and achieving or maintaining a healthy weight.

In line with this idea, less effective inhibitory control is associated with increased food intake and overeating (Guerrieri, 
Nederkoorn, \& Jansen, 2007; Guerrieri et al., 2007), increased bodyweight and obesity (Guerrieri, Nederkoorn, \& Jansen, 2008; Nederkoorn, Braet, Van Eijs, Tanghe, \& Jansen, 2006; Nederkoorn, Smulders, Havermans, Roefs, \& Jansen, 2006; Verbeken, Braet, Claus, Nederkoorn, \& Oosterlaan, 2009), and less weight loss during treatment (Nederkoorn, Jansen, Mulkens, \& Jansen, 2007). Moreover, recent research suggests that overweight and obesity are not so much related to inhibitory control in general, but rather to food-specific inhibitory control deficits (Houben, Nederkoorn, \& Jansen, 2014; Nederkoorn, Coelho, Guerrieri, Houben, \& Jansen, 2012). Thus, the available evidence supports a crucial role for inhibitory control, in particular when confronted with tasty foods, in the prevention and treatment of excessive bodyweight and obesity.

These findings subsequently prompted many studies that examined the possibility of training inhibitory control to reduce food intake and overweight (Houben, 2011; Houben \& Jansen, 2011; Koningsbruggen, Veling, Stroebe, \& Aarts, 2013; Veling, Aarts, \& Papies, 2011; Veling, Aarts, \& Stroebe, 2013; Veling, van Koningsbruggen, Aarts, \& Stroebe, 2014). Overall, these studies show that training the inhibition of responses to food reduces choices for those foods that were consistently paired with stopping or inhibiting a response (Koningsbruggen et al., 2013; Veling et al., 2013), decreases consumption of those foods (Houben, 2011; Houben \& Jansen, 2011; Veling et al., 2011) and facilitates weight loss (Veling et al., 2014). Similar results were demonstrated also in other domains like excessive alcohol consumption (Bowley et al., 2013; Houben, Havermans, Nederkoorn, \& Jansen, 2012; Houben, Nederkoorn, Wiers, \& Jansen, 2011; Jones \& Field, 2013).

Though promising as a means of promoting behavioral change, the mechanisms underlying the effects of this kind of inhibition training still remain unclear. Current literature on training inhibitory control suggests that improvements may follow either from the strengthening of top-down, controlled inhibition or from the development of automatic forms of inhibition (Verbruggen \& Logan, 2008). Recent evidence suggests it is unlikely that this kind of inhibition training operates by strengthening general, top-down inhibitory control abilities. First, general inhibition training has shown rather disappointing results in both the food domain (Guerrieri, Nederkoorn, \& Jansen, 2012) and the alcohol domain (Jones \& Field, 2013), suggesting that stimulus-specific training may be more effective in changing health behavior. Second, stimulus-specific training failed to produce significant improvements on general response inhibition, while results did show behavioral change (i.e., less undesired specific behavior) following training (Houben et al., 2012). Hence, the available evidence does not support the idea that food-specific inhibition training strengthens top-down inhibitory control. However, it has not yet been examined whether this kind of inhibition training may facilitate bottom-up, automatic inhibitory control.

Importantly, it has been suggested that, in conditions where certain stimuli are consistently and repeatedly paired with stop cues, people may gradually learn to associate these stimuli with stopping (Verbruggen \& Logan, 2008). Once such associations are established, the stimuli may directly elicit inhibition, thereby bypassing slow, top-down inhibitory control, and facilitating the stopping process. Whether such automatic inhibitory processes are indeed induced by food-specific inhibition training has not yet been investigated. The aim of the current study therefore was to examine whether consistently pairing food-related stimuli with stop cues indeed induces automatic associations between those stimuli and stopping. To examine this hypothesis, participants performed a Go/ No-Go training task during which pictures of chocolate were consistently paired with stop cues or always paired with go cues. Following the Go/No-Go task, we assessed automatic associations between chocolate and stopping versus going, desire to eat and chocolate consumption during a bogus taste test. It was hypothesized that the consistent pairing of chocolate with inhibition cues would induce automatic associations between chocolate and stopping. Further, in replication of our previous research (Houben \& Jansen, 2011), we expected that participants who consistently inhibited their responses to chocolate would report less desire to eat and would show reduced food intake relative to participants who were allowed to respond to chocolate.

\section{Method}

\section{Participants}

Fifty-two female undergraduate students were recruited from the student population at Maastricht University using advertisements posted in the university buildings and the Psychology department's online study participation system. ${ }^{1}$ The advertisements asked for female volunteers, who liked to eat chocolate on a regular basis, to participate in experimental research. Participants were excluded if they had severe to moderate underweight $(\mathrm{BMI}<18.5)$, disliked the chocolate that was presented during the taste test (mean rating $<5$ ), or were outliers (more than 2.5 standard deviations from their group mean) on one of the dependent measures (SCIAT score, desire to eat, or food intake during the taste test). These exclusions resulted in a final sample of 41 participants (chocolate/no-go: $n=21$; chocolate/go: $n=20$ ). Participants were aged $18-25$ years $(M=20.13, S D=1.73)$. The two conditions were well matched in terms of age, BMI, dietary restraint, trait chocolate craving, and taste ratings (see Table 1 ). The study protocol was approved by the local ethical committee of the Faculty of Psychology and Neuroscience.

\section{Materials and measures}

\section{Go/no-go task}

The Go/No-Go task consisted of 2 blocks of 160 trials. During each block, participants were presented with pictures and were instructed to press the space bar when a go cue was displayed on the picture, and to refrain from responding when a no-go cue was displayed on the picture. The go and no-go cues were the letters ' $p$ ' and ' $\mathrm{f}$ ', which were displayed randomly in one of four corners of the pictures. Go/no-go instructions were counterbalanced so that the letter 'p' was the go cue (and 'f' the no-go cue) for half the participants, and for the other half of participants, 'p' was the no-go cue (and ' $\mathrm{f}$ ' the go cue). Stimuli consisted of four pictures of chocolate snacks (a mixture of different types of chocolate including milk chocolate, plain chocolate, and chocolate with nuts or caramel), four neutral pictures of empty plates, and 8 filler pictures (snack foods; e.g., crisps, nuts). Filler stimuli were used to mask the goal of the study and to avoid demand characteristics. ${ }^{2}$ Each trial simultaneously presented a picture and a go/no-go cue (1000 ms). Participants had to respond by pressing the space bar when the picture was accompanied by the go cue, but had to refrain from responding when the picture was accompanied by the no-go cue. A green circle was displayed after a correct (non)response $(500 \mathrm{~ms})$, and a red cross an after incorrect (non)response (500 ms). The inter-trial interval was $500 \mathrm{~ms}$.

Participants were randomly assigned to one of two conditions. In the chocolate/no-go condition $(n=26)$, chocolate-related pictures were consistently paired with the no-go cue, while pictures of empty plates were consistently paired with the go cue. The eight filler pictures were presented with the go cue on half the trials and

\footnotetext{
1 This sample size yielded $80 \%$ power to detect medium to large group differences ( $\mathrm{f} \geq .40$ ).

2 Before debriefing, participants were asked about their ideas regarding the goal of the study. None of the participants correctly guessed the purpose of the study.
} 
Table 1

Characteristics of participants in the two experimental conditions, with significance tests.

\begin{tabular}{|c|c|c|c|}
\hline & Chocolate/go condition & Chocolate/no-go condition & $F$-tests \\
\hline Age & 19.70 years $(1.46)$ & 20.55 years $(1.91)^{\mathrm{a}}$ & $F(1,38)=2.52, p=.12$ \\
\hline BMI & $21.77 \mathrm{~kg} / \mathrm{m}^{2}(2.39)$ & $22.58 \mathrm{~kg} / \mathrm{m}^{2}(3.46)$ & $F(1,39)=.75, p=.39$ \\
\hline Restraint & $12.10(5.59)$ & $11.81(4.12)$ & $F(1,39)=.04, p=.85$ \\
\hline Taste ratings & $7.45(.99)$ & $7.24(.73)$ & $F(1,39)=.61, p=.44$ \\
\hline Trait chocolate craving & $-.55(10.18)$ & $1.48(8.42)$ & $F(1,39)=.48, p=.49$ \\
\hline
\end{tabular}

a Data missing from one participant in this condition.

with the no-go cue on the other half of the trails. In the chocolate/ go condition $(n=26)$, chocolate-related pictures were always paired with the go cue, and pictures of empty plates were always paired with the no-go cue. The eight filler pictures were presented with the go cue on half the trials and with the no-go cue on the other half of the trails. In each condition, all stimuli were presented ten times in both blocks. Go and no-go trials were always presented in random order.

\section{Single-category implicit association test}

A Single-Category Implicit Association Test (SCIAT; Karpinski \& Steinman, 2006) was used to assess implicit associations between chocolate and stopping versus going. The SCIAT consisted of three blocks. In block 1 (16 trials), participants sorted pictures into the attribute categories 'stop' versus 'go' using two response keys on the keyboard. The 'stop' pictures were four pictures that were related to stopping (i.e., a traffic light signaling stop, a red cross, a stop traffic sign, a hand signaling stop), and the 'go' pictures were four pictures that were related to going (i.e., a traffic light signaling walk, a green checkmark, a mandatory direction traffic sign, an arrow signaling go). In block 2 (48 trials), participants sorted stimuli of one attribute category and the chocolate target category with one response key, and items from the other attribute category with the other key (e.g., stop + chocolate vs. go). The chocolate category consisted of the same four pictures of chocolate that were also used during the Go/No-Go task. In block 3 (48 trials), the response assignment of the chocolate target category was reversed and participants performed the reversed combination (e.g., stop vs. go + chocolate).

To keep the number of left and right responses comparable in blocks 2 and 3, chocolate-related pictures were presented on 20 trials, attributes assigned to the same response key as chocolate were presented on 8 trials, and attributes assigned to the other response key were presented on 20 trials. The response assignment of the target and attribute categories was counterbalanced across participants so that half the participants classified chocolate together with 'stop' in the first block while the other half of the participants started out by classifying chocolate together with 'go'. Also, half the participants sorted 'stop' stimuli using a right response key and 'go' using the left response key, whereas the other half of the participants received the reverse instructions. Stimuli were always presented in the middle of the computer screen and the labels of the categories assigned to the left and right response key were presented in the corresponding upper corners of the computer screen.

\section{Taste test}

Chocolate consumption was measured using a bogus taste test. During the taste test, participants were presented three bowls, each containing about 650 grams of one of three types of chocolates: Milk chocolate (Schogetten Alpenvollmilch; 560 kcal/100gr), dark chocolate (Schogetten Zartbitter; $530 \mathrm{kcal} / 100 \mathrm{gr}$ ), or milk chocolate containing nuts (Schogetten Alpenvollmilch-Haselnuss; $575 \mathrm{kcal} / 100 \mathrm{gr}$ ). Participants were instructed that they were allowed to consume as much or as little of the chocolate as they wished to complete the taste test. Together with the bowls of chocolate they were handed a questionnaire. This questionnaire asked participants to first indicate how much they desired to eat the food on a $100 \mathrm{~mm}$ Visual Analogue Scale $(0=$ no desire at all; $100=$ strong desire). Next, they were asked to compare the different types of chocolate on a number dimensions including the texture, taste, and nutrients. Finally, they were asked to rate the taste of each type of chocolate by assigning a number (0-10). After $10 \mathrm{~min}$, the experimenter removed the bowls of chocolate and the amount of chocolate consumed was measured outside the test room.

\section{Trait chocolate craving}

Participants' trait chocolate craving was measured with the chocolate craving subscale of the Attitudes to Chocolate Questionnaire (ACQ; Benton, Greenfield, \& Morgan, 1998). The chocolate craving subscale of the ACQ consists of 10 items that measure the amount of chocolate craving, with higher scores indicating stronger chocolate craving. Every item of the craving subscale presented a statement regarding the experience of craving for chocolate. Participants indicated on a 7-point Likert scale whether or not the statement matched their own feelings $(-3=$ not at all like me; $3=$ very much like me).

\section{Dietary restraint}

Dietary restraint was measured using the revised Restraint Scale (RS; Herman \& Polivy, 1980). The RS is a self-report questionnaire consisting of 10 items assessing concern for dieting and weight fluctuations. The maximum score on this scale is 35 , while the minimum score is 0 . Higher scores indicate an increased intention to restrict food intake.

\section{Body mass index}

Participants' weight and height were assessed in order to calculate participants' Body Mass Index ( $\mathrm{kg} / \mathrm{m}^{2}$; BMI). Participants were weighed with their clothes on, but we asked them to remove their shoes, jackets and to empty their pockets (e.g., cell phones, keys, etc.).

\section{Procedure}

Participants were asked not to eat anything for $2 \mathrm{~h}$ before the start of the study to control for different states of hunger between the conditions at the start of the experiment. Testing was completed between $10 \mathrm{am}$ and $5 \mathrm{pm}$. After signing a written statement of informed consent, participants filled out the craving subscale of the ACQ. Next, participants were randomly assigned to the chocolate/ no-go condition or the chocolate/go condition, and they performed the Go/No-Go task. After the Go/No-Go task, participants performed the bogus taste test and the SCIAT, in balanced order. Finally, participants filled out the RS and weight and length were measured to calculate BMI. At the end of the study, all participants were thanked for their cooperation and received course credits or a gift certificate as remuneration for their participation. 
Statistical analyses

We used Univariate Analyses of Covariance (ANCOVA) to examine differences between the chocolate/no-go condition and the chocolate/ go condition on the dependent measures. Condition was always entered as the between-subjects factor in the analyses. Trait chocolate craving was entered as a covariate in all analyses given the large variability on this measure across participants in both conditions (see Table 1). The dependent measures were SCIAT scores, and desire to eat as well as food intake in total grams during the taste test. The SCIAT was scored using the D600 scoring algorithm (Greenwald, Nosek, \& Banaji, 2003) so that higher scores indicate stronger implicit associations between chocolate and 'go'.

\section{Results}

First, we examined the effect of the Go/No-Go manipulation on implicit associations between chocolate and stopping versus going. Results showed no significant effect of trait chocolate craving on SCIAT scores, $F(1,38)=.17, p=.68, \eta^{2} p=.01$. The effect of condition on SCIAT scores was significant, $F(1,38)=6.07, p=.02, \eta_{p}^{2}=.14$, indicating that participants in the chocolate/no-go condition associated chocolate less strongly with going compared to participants in the chocolate/go condition (see Fig. 1). Thus, chocolate-go associations were significantly reduced in the chocolate/no-go condition relative to the chocolate/go condition. Follow-up one-sample t-tests, however, showed that participants in both the chocolate/go condition and the chocolate/no-go condition still significantly associated chocolate more strongly with 'go' than with 'stop', $t(19)=7.74$, $p<.001$ and $t(20)=2.93, p<.01$ respectively.

Next, we examined the effect of the manipulation on desire to eat and actual food intake during the taste test. With respect to desire to eat, results showed a significant effect of condition, $F(1,38)=4.66$, $p=.04, \eta_{p}^{2}=.11$, while trait chocolate craving did not significantly influence desire to eat, $F(1,38)=.62, p=.44, \eta^{2} p=.02$. Inspection of the mean desire scores showed that participants in the chocolate/ no-go condition reported less desire to eat than participants in the chocolate/go condition (see Fig. 1). In addition, participants in the chocolate/no-go condition consumed significantly less chocolate during the taste test compared to participants in the chocolate/go condition, $F(1,38)=4.12, p<.05, \eta^{2}=.10$ (see Fig. 1 ). Specifically, participants in the chocolate/no-go condition consumed on average 29.45 grams of chocolate, which corresponds to an average energy intake of $164.26 \mathrm{kcal},(S D=65.02)$. Participants in the chocolate/ go condition, in contrast consumed 37.91 grams of chocolate, or $211.19 \mathrm{kcal}(S D=90.04)$. Trait chocolate craving did not significantly influence food intake during the taste test, $F(1,38)=.98, p=.33$, $\eta_{p}^{2}=.03$.

\section{Discussion}

Recent evidence suggests that inhibiting impulses does not necessarily have to be an effortful top-down process, but can also be triggered in an automatic, bottom-up fashion via the retrieval of learned stimulus-stop associations (Verbruggen \& Logan, 2008). This development of automatic inhibition could explain recent findings that the consistent pairing of food stimuli with stop cues reduces food intake and bodyweight (e.g., Houben, 2011, Houben \& Jansen, 2011; Veling et al., 2011, 2014). Specifically, the repeated pairing of food stimuli with stopping may have caused participants to gradually develop food-stop associations. These automatic inhibition associations may subsequently have facilitated inhibitory control, thereby decreasing food intake. The aim of the present study was to examine this automatic inhibition account. We used the same Go/No-Go paradigm that proved effective in changing eating behavior in previous studies (e.g., Houben \& Jansen, 2011). In this
SCIAT score
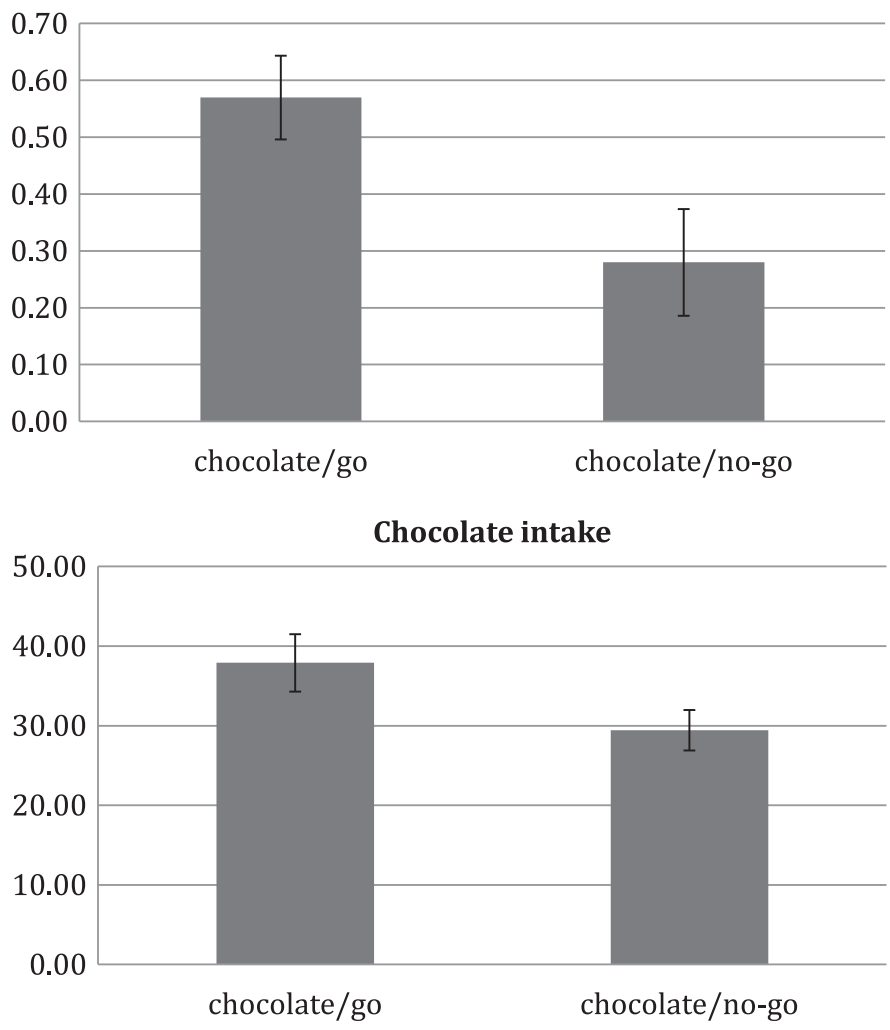

Desire to eat

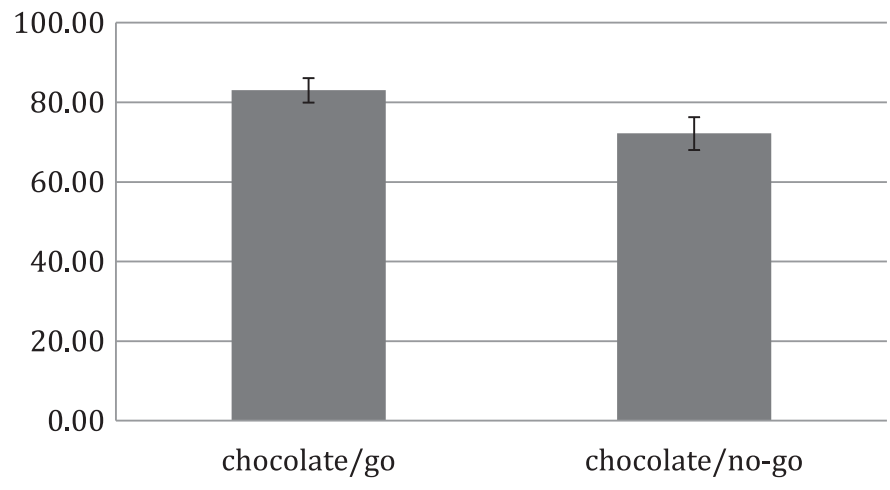

Fig. 1. Means and standard errors for the SCIAT (D600 score), desire to eat ( $100 \mathrm{~mm}$ VAS), and chocolate intake (grams), separately per condition.

paradigm, pictures of chocolate stimuli were consistently paired with stop cues in the chocolate/no-go condition, while participants in the chocolate/go condition were allowed to respond to chocolate. After training, we measured automatic associations between chocolate and stopping versus going, food intake and desire to eat. As hypothesized, the consistent go/no-go mapping of chocolate stimuli to stop cues induced automatic inhibition associations: Relative to the chocolate/go condition, automatic chocolate-go associations were reduced, participants showed less desire to eat, and consumed less chocolate in the chocolate/no-go condition.

First, the present findings clearly show that associations with 'go' were markedly and significantly lower in the chocolate/no-go condition compared to the chocolate/go condition. These results therefore show that the consistent mapping of chocolate to go versus stop cues influences automatic associations, consistent with the automatic inhibition hypothesis (Verbruggen \& Logan, 2008). Once learned, these automatic associations may facilitate inhibitory control, 
without the need for effortful, top-down regulatory processes. It is, however, important to note that one single session of training was not enough to induce automatic associations between chocolate and 'stop'. In both conditions, participants showed automatic associations between chocolate and 'go', which would be consistent with a behavioral impulse to obtain and consume the food. While these automatic associations were reduced following the consistent mapping of chocolate onto stop cues, the manipulation clearly was not strong enough to completely reverse these associations (though caution is required when interpreting (SC)IAT effects in absolute terms as one cannot claim with any confidence that a zero (SC)IAT score maps onto a true neutral midpoint; Blanton \& Jaccard, 2006). Therefore, it could be interesting for future research to examine whether more extensive or frequent training would succeed in inducing stop associations with the food stimuli. Longer or repeated training that includes more food-stop pairings may aid in the development of automatic inhibition, which presumably needs some time to build.

Second, in replication of previous results (Houben, 2011; Houben \& Jansen, 2011; Veling et al., 2011, 2013), we demonstrated that participants reported less desire to eat and also ate less chocolate following a chocolate-stop training compared to a chocolate. Hence, together these findings attest to effectiveness of food-specific inhibition as a means to change intake of high calorie foods and thereby reduce excessive bodyweight. It should be noted, however, that although a $2 \mathrm{~h}$ fast was implemented to control for appetite and hunger, we did not check whether participants complied with these instructions. Consequently, it is possible that the differences in desire to eat and food intake between the two conditions also reflect differences in appetite. We consider this unlikely given the experimental design in which participants were randomly assigned to conditions. Nevertheless, it would be good to rule out this possibility in future research by adding baseline measures of appetite. In addition, the longevity of training effects on eating behavior and bodyweight is still largely unexamined, although at least one study already found effects on bodyweight following a four-week training period (Veling et al., 2014). Nevertheless, this is still a relatively short time frame and future research is needed to further examine long-term effects of food inhibition training. It is likely that the amount of training also contributes to the persistence of behavioral effects, so it would be interesting to vary the amount of training to gain knowledge about the specific task parameters that are required to achieve long-term effects on food intake and bodyweight. Finally, future studies should also investigate the effectiveness of this type of training in an overweight sample before any definite conclusions can be reached regarding the value of this training as an intervention to reduce excessive weight and obesity.

Unlike in the previous study where we used a chocolate Go/NoGo inhibition training (Houben \& Jansen, 2011), no control condition was included in the present study with inconsistent (50/50) go/ stop responses to chocolate stimuli. Note, however, that inconsistent and consistent go-mappings could both encourage participants to respond more impulsively toward food and consume more as they both require participants to respond to food stimuli (at least half the time), which may have increased attention and assigned value for those stimuli (Schonberg et al., 2014). So there is really no reason to assume that an inconsistent control condition would have been a better alternative to the chocolate/go condition that was used in this study. Unfortunately, with these types of research it is difficult to find an appropriate control condition and it is therefore often difficult to truly quantify the effectiveness of inhibition training. However, across studies, researchers have now used many different control conditions, including food-go conditions (Koningsbruggen et al., 2013; Veling et al., 2011, 2013), inconsistent food-stop/go conditions (Houben, 2011; Houben \&
Jansen, 2011), and even neutral non-food control conditions (Veling et al., 2014), and still a fairly consistent picture is emerging that indicates genuine behavioral effects of food (and alcohol) inhibition training, regardless of the exact control condition that was used. Moreover, at least one study has used a repeated measures design to demonstrate behavioral change following training compared to baseline. Though more of this kind of longitudinal research (with different control conditions) is needed before the effectiveness of inhibition training can be conclusively established, together these studies do suggest that this is an approach worthy of further investigation.

In conclusion, food-specific inhibition training wherein food cues are repeatedly and consistently mapped onto stopping (i.e., inhibiting responses) has been shown to decrease consumption of those food items and even decrease body weight (e.g., Houben, 2011; Houben \& Jansen, 2011; Koningsbruggen et al., 2013; Veling et al., 2011, Veling et al., 2013; Veling et al., 2014). The present study adds to this body of knowledge by showing that food-specific inhibition training causes people to gradually associate food less with going and more with stopping. Hence, the consistent mappings of food onto stop signals paves the way for the development of automatic food-stop associations that, once established, are activated upon encountering the food cues and facilitate automatic inhibition (cf. Verbruggen \& Logan, 2008). Such automatic inhibition associations may be particularly useful in prevention and intervention as they bypass the need for effortful self-regulation.

\section{References}

Benton, D., Greenfield, K., \& Morgan, M. (1998). The development of the attitudes to chocolate questionnaire. Personality and Individual Differences, 24(4), 513-520.

Blanton, H., \& Jaccard, J. (2006). Arbitrary metrics in psychology. The American Psychologist, 61(1), 27-41.

Bowley, C., Faricy, C., Hegarty, B., J Johnstone, S., L Smith, J., J Kelly, P., et al. (2013). The effects of inhibitory control training on alcohol consumption, implicit alcohol-related cognitions and brain electrical activity. International Journal of Psychophysiology, 89(3), 342-348.

Finucane, M. M., Stevens, G. A., Cowan, M. J., Danaei, G., Lin, J. K., Paciorek, C. J., et al (2011). National, regional, and global trends in body-mass index since 1980 Systematic analysis of health examination surveys and epidemiological studies with 960 country-years and 9.1 million participants. The Lancet, 377(9765), 557-567.

Greenwald, A. G., Nosek, B. A., \& Banaji, M. R. (2003). Understanding and using the implicit association test. I. An improved scoring algorithm. Journal of Personality and Social Psychology, 85(2), 197-216.

Guerrieri, R., Nederkoorn, C., \& Jansen, A. (2007). How impulsiveness and variety influence food intake in a sample of healthy women. Appetite, 48(1), 119-122.

Guerrieri, R., Nederkoorn, C., \& Jansen, A. (2008). The interaction between impulsivity and a varied food environment. Its influence on food intake and overweight. International Journal of Obesity, 32(4), 708-714.

Guerrieri, R., Nederkoorn, C., \& Jansen, A. (2012). Disinhibition is easier learned than inhibition. The effects of (dis) inhibition training on food intake. Appetite, 59(1), 96-99.

Guerrieri, R., Nederkoorn, C., Stankiewicz, K., Alberts, H., Geschwind, N., Martijn, C. et al. (2007). The influence of trait and induced state impulsivity on food intake in normal-weight healthy women. Appetite, 49(1), 66-73.

Herman, C. P., \& Polivy, J. P. (1980). Restrained eating. In A. J. Stunkard (Ed.), Obesity (pp. 208-225). Philadelphia: Saunders.

Hofmann, W., Friese, M., \& Strack, F. (2009). Impulse and self-control from a dual-systems perspective. Perspectives on Psychological Science, 4(2), 162-176.

Houben, K. (2011). Overcoming the urge to splurge. Influencing eating behavior by manipulating inhibitory control. Journal of Behavior Therapy and Experimental Psychiatry, 42(3), 384-388.

Houben, K., Havermans, R. C., Nederkoorn, C., \& Jansen, A. (2012). Beer à No-Go. Learning to stop responding to alcohol cues reduces alcohol intake via reduced affective associations rather than increased response inhibition. Addiction (Abingdon, England), 107(7), 1280-1287.

Houben, K., \& Jansen, A. (2011). Training inhibitory control. A recipe for resisting sweet temptations. Appetite, 56(2), 345-349.

Houben, K., Nederkoorn, C., \& Jansen, A. (2014). Eating on impulse. The relation between overweight and food-specific inhibitory control. Obesity, 22(5), E6-E8.

Houben, K., Nederkoorn, C., Wiers, R. W., \& Jansen, A. (2011). Resisting temptation. Decreasing alcohol-related affect and drinking behavior by training response inhibition. Drug and Alcohol Dependence, 116(1), 132-136.

Jones, A., \& Field, M. (2013). The effects of cue-specific inhibition training on alcohol consumption in heavy social drinkers. Experimental and Clinical Psychopharmacology, 21(1), 8-16. 
Karpinski, A., \& Steinman, R. B. (2006). The single category implicit association test as a measure of implicit social cognition. Journal of Personality and Social Psychology, 91(1), 16

Koningsbruggen, G. M., Veling, H., Stroebe, W., \& Aarts, H. (2013). Comparing two psychological interventions in reducing impulsive processes of eating behaviour. Effects on self-selected portion size. British Journal of Health Psychology, 19(4), 767-782.

Nederkoorn, C., Braet, C., Van Eijs, Y., Tanghe, A., \& Jansen, A. (2006). Why obese children cannot resist food. The role of impulsivity. Eating Behaviors, 7(4), 315-322.

Nederkoorn, C., Coelho, J. S., Guerrieri, R., Houben, K., \& Jansen, A. (2012). Specificity of the failure to inhibit responses in overweight children. Appetite, 59(2), 409413.

Nederkoorn, C., Jansen, E., Mulkens, S., \& Jansen, A. (2007). Impulsivity predicts treatment outcome in obese children. Behaviour Research and Therapy, 45(5), 1071-1075.

Nederkoorn, C., Smulders, F. T., Havermans, R. C., Roefs, A., \& Jansen, A. (2006). Impulsivity in obese women. Appetite, 47(2), 253-256.

Schonberg, T., Bakkour, A., Hover, A. M., Mumford, J. A., Nagar, L., Perez, J., et al. (2014). Changing value through cued approach. An automatic mechanism of behavior change. Nature Neuroscience, 17(4), 625-630.

Strack, F., \& Deutsch, R. (2004). Reflective and impulsive determinants of social behavior. Personality and Social Psychology Review, 8, 220-247.
Tangney, J. P., Baumeister, R. F., \& Boone, A. L. (2004). High self-control predicts good adjustment, less pathology, better grades, and interpersonal success. Journal of Personality, 72(2), 271-324.

Veling, H., Aarts, H., \& Papies, E. K. (2011). Using stop signals to inhibit chronic dieters' responses toward palatable foods. Behaviour Research and Therapy, 49(11), 771-780.

Veling, H., Aarts, H., \& Stroebe, W. (2013). Using stop signals to reduce impulsive choices for palatable unhealthy foods. British Journal of Health Psychology, 18(2), 354-368.

Veling, H., van Koningsbruggen, G. M., Aarts, H., \& Stroebe, W. (2014). Targeting impulsive processes of eating behavior via the internet. Effects on body weight. Appetite, 78, 102-109.

Verbeken, S., Braet, C., Claus, L., Nederkoorn, C., \& Oosterlaan, J. (2009). Childhood obesity and impulsivity. An investigation with performance-based measures. Behaviour Change, 26(03), 153-167.

Verbruggen, F., \& Logan, G. D. (2008). Automatic and controlled response inhibition. Associative learning in the go/no-go and stop-signal paradigms. Journal of Experimental Psychology. General, 137(4), 649-672.

World Health Organization. (2009). Global health risks. Mortality and burden of disease attributable to selected major risks. Geneva: World Health Organization. 